\title{
Working
}

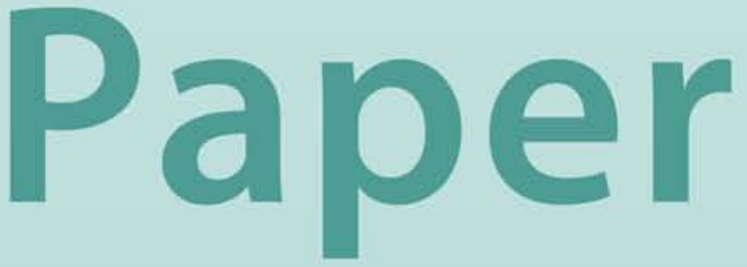




\section{Macroeconomic Effects and Policy Challenges of Population Aging}

Natalia T. Tamirisa and Hamid Faruqee 


\title{
IMF Working Paper
}

European Department

\section{Macroeconomic Effects and Policy Challenges of Population Aging Prepared by Natalia T. Tamirisa and Hamid Faruqee ${ }^{1}$}

Authorized for distribution by Juan Jose Fernández-Ansola

April 2006

\begin{abstract}

\section{This Working Paper should not be reported as representing the views of the IMF.} The views expressed in this Working Paper are those of the author(s) and do not necessarily represent those of the IMF or IMF policy. Working Papers describe research in progress by the author(s) and are published to elicit comments and to further debate.
\end{abstract}

This paper simulates the macroeconomic effects of population aging in a dynamic overlapping generations model of a small open economy. The model is calibrated to data for the Czech Republic, where population aging is proceeding at a pace comparable to that in other advanced countries in Europe. Simulations show that population aging is likely to slow economic growth and improvements in living standards. Although reforms to raise labor force participation and productivity growth can mitigate these adverse effects, they are unlikely to eliminate the need for fiscal reforms. The budget will come under pressure from rising age-related expenditures, and consolidation will be needed to preserve debt sustainability.

JEL Classification Numbers: J14, H55, F47

Keywords: Population, aging, simulation, general equilibrium model Author(s) E-Mail Address: ntamirisa@,imf.org, hfaruqee@,imf.org

\footnotetext{
${ }^{1}$ The authors are grateful to Juan Jose Fernández-Ansola, Giovanni Ganelli, Anita Tuladhar, and participants in seminars at the Czech National Bank and the IMF's European Department for helpful comments.
} 


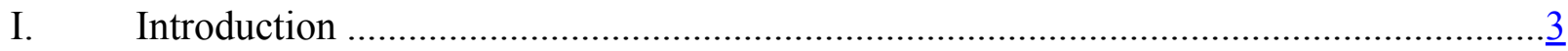

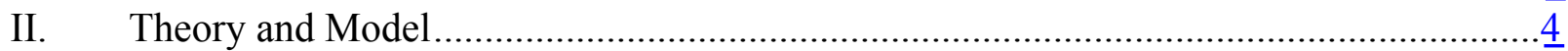

III. Calibration and Experiments........................................................................... $\underline{5}$

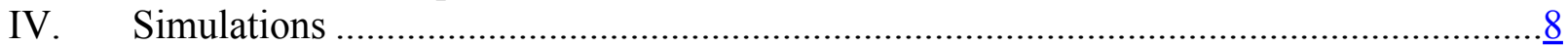

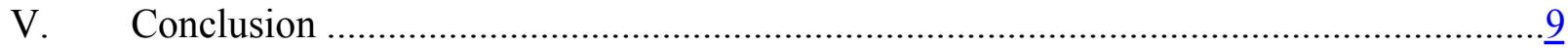

\section{Figures}

1. Macroeconomic Effects of Population Aging....................................................... 13

2. Delayed Fiscal Consolidation ....................................................................... 14

3. No Consolidation Scenario ........................................................................ $\frac{15}{16}$

4. Labor Market Reforms and Labor-Augmenting Techological Change........................ 16

Appendix

I. The Description of the Model .......................................................................... 17

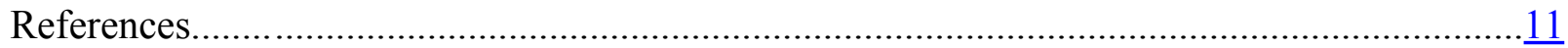




\section{INTRODUCTION}

Lower fertility rates and rising longevity are causing a gradual decline in population growth in advanced countries and a shift in the age structure of the population toward a greater share of the elderly. How would population aging affect economic growth, public finances, and the current account? How can adverse macroeconomic effects of population aging be mitigated through public policy?

We explore these issues in a dynamic overlapping generations model of a small open economy. The model shares many of the features found in the IMF's global macroeconomic simulation model, MULTIMOD, but is extended to incorporate demographic and life-cycle dynamics, following Faruqee (2002). It allows us to examine diverse macroeconomic implications of population aging and consider a gamut of policy responses to population aging. The model is calibrated to data for the Czech Republic - a country where population aging is proceeding at a fast clip, comparable to that experienced in many industrial countries in Europe. By 2050, the elderly are projected to account for more than half of the Czech population.
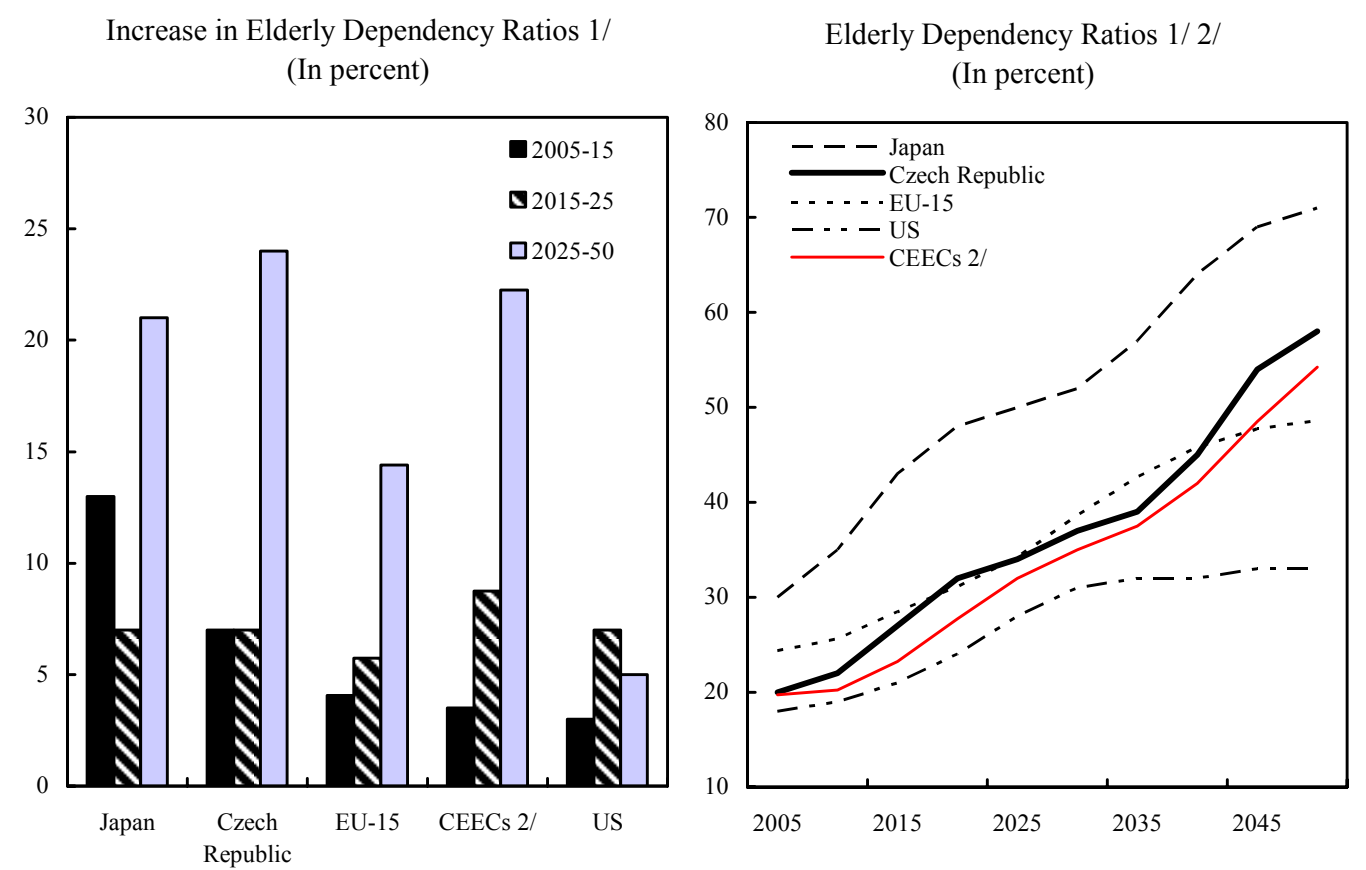

Source: United Nations.

$1 /$ The ratio of the population aged 65 and above to the population aged 15-64.

2/ Average for Hungary, Poland, Slovakia, and Slovenia.

Simulations show that population aging will have significant effects on the economy and public finances in the coming years. A decline in the working-age population, which accompanies population aging, is likely to slow growth in real GDP and improvements in living standards. Although reforms to raise labor force participation and productivity growth can help mitigate these adverse effects, they are unlikely to eliminate the need for structural fiscal reforms. The budget is expected to come gradually under pressure from rising 
expenditures on pensions and health care. Consolidation will be needed to preserve debt sustainability. The earlier it starts, the smaller will be the fiscal adjustment needed to close the fiscal gap.

The rest of the paper is organized as follows: Section II briefly discusses the conceptual framework for the analysis. The detailed description of the model is provided in the Appendix. Section III explains how the model was calibrated to the Czech data. It also describes the policy experiments considered in the paper. Section IV presents simulation results and discusses their policy implications. Section V concludes.

\section{THEORY AND MODEL}

The model is a dynamic general equilibrium system with forward-looking behavior and model-consistent expectations. Consumption-saving behavior is based on Blanchard's (1985) model, where agents are assumed to have finite planning horizons. The production function is of the Cobb-Douglas form with capital and labor. Investment behavior is based on Tobin's q-theory, whereby the desired rate of investment exceeds the steady-state rate as long as the expected marginal product of capital is greater than its replacement cost. On the external side, import volumes depend on the main components of aggregate demand, and exports reflect the foreign import demand functions. Exchange rates and interest rates are linked by the interest parity condition. The real exchange rate equilibrates the goods markets and ensures consistency between flow relationships and consumers' desired rates of asset accumulation. International capital markets are assumed to be perfect, allowing the small open economy to borrow freely at the prevailing world interest rate. Government absorption is exogenous; and an endogenous aggregate tax rate ensures that the ratio of government debt to GDP converges to a target level. See the Appendix for a detailed description of the model. ${ }^{2}$

The key channels through which demographic changes affects the economy in the model involve the life-cycle profiles of individuals' earnings (Faruqee, 2002). ${ }^{3}$ Empirically, these profiles typically have a hump-shaped pattern: earnings rise, as young individuals enter the labor force and start gaining work experience, peak at middle age, and decline as individuals move into retirement. On the supply side, age-earnings profiles reflect changes in relative productivity and labor supply over an individual's working life. Changes in the age structure of the population thus affect aggregate labor supply, through differences in relative productivity and individual labor supply. On the demand side, individuals are assumed to adjust their savings and smooth consumption based on their anticipated path of life-cycle income. Younger individuals tend to be net borrowers, because their current income is below their permanent income. ${ }^{4}$ Mature agents, at the peak of their income potential, save in anticipation of retirement. The elderly also save (albeit to a lesser extent) in this model, given

\footnotetext{
${ }^{2}$ For details on the Fund's simulation model, MULTIMOD, see Laxton and others (1998).

${ }^{3}$ For an application of the model to the analysis of population aging in other countries, see Faruqee (2002) and Faruqee and Mühleisen (2003).

${ }^{4}$ Liquidity or borrowing constraints could, of course, affect this behavior; see Faruqee and Laxton (2000) for a discussion on introducing such constraints in this type of framework.
} 
uncertainty about their lifetimes (i.e., longevity risk). ${ }^{5}$ Changes in the age composition of the population thus impact aggregate consumption and saving.

\section{CALIBRATION AND EXPERIMENTS}

Age-earnings profiles were estimated using the Czech Statistical Office's data on wagebased salaries by age cohort for the period 1996-2003. The data on labor earnings were adjusted by the labor force participation rates and normalized relative to per capita earnings of the youngest working cohort (text figure). ${ }^{6}$

The resulting crosssectional age-earnings profiles were taken to represent the time-series pattern of individuals' relative earnings over their lifetime according to the fit of the following exponential function:

$$
r y(s, t)=a_{1} e^{-\alpha_{1}(t-s)}+a_{2} e^{-\alpha_{2}(t-s)}+a_{3} e^{-\alpha_{3}(t-s)},
$$

where $r y$ is relative labor income, $s$ and $t$ are cohort and time indices, respectively; and the difference $t-s$ is the age of a given cohort. This particular exponential form makes the model tractable and ensures a reasonable fit of the data. The first two terms are intended to capture the change in an individual's labor supply (for example, the number of hours worked) over the lifetime. The last term reflects productivity gains associated with age and experience. ${ }^{7}$ The fitted values are shown by the solid line in the text figure. Using the nonlinear least squares method, the parameter values in equation (1) were estimated to be: $\alpha_{1}=0.09 ; \alpha_{2}=0.12$; and $\alpha_{3}=0.10$; all significant at the 5 percent level.

\footnotetext{
${ }^{5}$ See, for example, Davies (1981) and Abel (1985). This empirical implication of the model is consistent with household survey data, which typically find positive savings rates for the old-age cohorts. See, for example, Browning and Lusardi (1996) and the references cited therein.

${ }^{6}$ We take the 20-24 year-olds to be the youngest working cohort. The labor force participation rates for the preceding, 15-19 year-old cohort are significantly below those for other working-age cohorts.

${ }^{7}$ There are restrictions on the coefficients in equation (1), for example, $a_{1}+a_{2}+a_{3}=1$. These restrictions are intended to generate non-negative hump-shaped profiles, which are normalized to unity for the youngest cohort (for which $s=t$ ). For more details, see Faruqee (2002).
} 
The model assumes that the relative age-earnings profiles - and hence, these parameters-remain stable over time. ${ }^{8}$ However, to the extent that healthier individuals would choose to postpone retirement and remain active in the labor force, the current age-earnings profiles would flatten in the future, mitigating the negative labor-supply impact of population aging on growth. In this study, however, this potential overestimation bias is alleviated by the fact that the fitted profiles are flatter for the old-age cohorts than the actual profiles based on the historical data.

Demographic projections are based on World Bank data. The main factor underlying population aging trends is the decline in fertility rates over the last half a century: from 2.69 children per woman in $1950-55$ to 1.17 in 2000-05. The World Bank's projections assume that the fertility rate will stabilize around 2015 and then rise gradually to the replacement rate, leading to a stationary population by 2100 . Under these projections, the elderly dependency ratio will peak in 2060 and then gradually stabilize by 2090 . The assumption that the elderly dependency ratio will stabilize at some point in the future is essential for ensuring the stability of the model. From the policy point of view, however, the choice of the demographic projections is less relevant, since the policy analysis in this chapter focuses on the period to 2050 , and for this period the World Bank projections are similar to those of the authorities and the United Nations. ${ }^{9}$ The demographic projections assume zero net migration, consistent with the historical data and the baseline assumption that current policies will continue. ${ }^{10}$ To ensure compatibility of the demographic data with the theoretical structure of the model, we redefine the key demographic rates with respect to the adult population. The declining fertility rates imply that

${ }^{8}$ Historically, age-earnings profiles have been fairly stable over time in the case of the United States and Japan; see Faruqee and Laxton (2000), and Faruqee and Muhleisen (2001), respectively. To the extent that ageearnings relationships change with aging, this would add confidence intervals around the (central) scenarios presented later.

${ }^{9}$ The authorities' analysis of long-term fiscal sustainability is based on the demographic projections prepared at the Charles University (available at www.reformaduchodu.cz). These projections are broadly similar to the United Nations' and the World Bank's projections up until 2050. Thereafter, the authorities' projections are more pessimistic than the World Bank's (the United Nations' projections are not available beyond 2050, see UN, 2004). The authorities assume that elderly dependency ratios continue to rise and population continues to decline beyond 2050 into the foreseeable future.

${ }^{10}$ Net migration flows are relatively small in the Czech Republic: less than $1 / 8$ percent of the population during 2000-04. See the website of the Czech Statistical Office (www.czso.cz). 
fewer young workers enter the labor force, and the adult population declines. As the share of the working-age people in the adult population falls, the share of the elderly rises (text figure).

The baseline was calibrated to reflect the key relevant features of the Czech economy in a long-run steady state. Real GDP growth in the Czech Republic is assumed to converge to that in the EU-15, taken to be about 2 percent per year. ${ }^{11}$ The population is assumed to remain stationary in the baseline, and hence the long-run per capita GDP growth also equals roughly 2 percent. Consumption is assumed to be inelastic with respect to the interest rate, i.e., the intertemporal elasticity of substitution is small $(0.4)$, while the rate of time preference is taken to be $2 \frac{1}{2}$ percent. As regards investment, a fixed equity risk premium is added to yield a reasonable capital-output ratio equal to 3 . The long-run real world interest rate is assumed to be 4 percent. The initial level of public debt is about 25 percent. Note that since the model simulates the effects of population aging in relative terms-as percent deviations from the baseline, the simulation results are fairly robust to the baseline assumptions.

Simulations focus on the macroeconomic effects of a population aging shock relative to the baseline of a stationary population. We first consider population aging under current policies, and then assuming that fiscal and structural policies are adjusted to offset the adverse effects of population aging:

- $\quad$ Demographic change. We assume that the elderly dependency ratio rises relative to the baseline of stationary population in line with demographic projections. By 2050 , the elderly dependency ratio increases by about $12 \frac{1}{2}$ percent compared to the baseline of a stationary population. This increase reflects a gradual decline in the fertility rate and a rise in longevity (a decline in the mortality rate).

- Fiscal consolidation. First we assume that consolidation is delayed by about 10 years, from 2020 to 2030; during this time, the government finances rising age-related expenditures through borrowing. Next we consider a scenario where the government does not take any special consolidation measures and finances the increase in agerelated expenditures exclusively through borrowing.

- $\quad$ Labor market reforms and technological change. Factors related to labor market reforms and technological change are assumed to augment growth in the effective labor supply (i.e., in productivity-adjusted terms) by an average rate of $1 / 3$ percent per year during the next 50 years, until 2050 (thereafter, the effective labor supply is assumed to gradually return to the baseline level). This boost to growth can come from several sources: (i) $1 / 3$ percent growth in the number of workers owing to an increase in the labor force participation rates, ${ }^{12}$ (ii) a labor-augmenting technological change raising labor productivity growth by $1 / 3$ percent per year; (iii) $1 / 3$ percent annual

\footnotetext{
${ }^{11}$ For recent potential growth estimates in the EU, see Chapter I in EC (2004).

${ }^{12}$ In the model, the increase in the effective labor supply could also reflect immigration, provided immigrants are of working age and are at least as productive as the resident population.
} 
growth in the number of hours worked; or a combination of these sources amounting to $1 / 3$ percent increase in annual growth in the effective labor supply during 2005-50. The needed increases in labor productivity and labor supply are significant (amounting to a cumulative increase of $171 / 2$ percent in the effective labor supply by 2050), and would require designing comprehensive and consistently effective reform strategies.

\section{Simulations}

Population aging is estimated to reduce GDP growth in the long run compared to the baseline scenario of a stationary population. By 2050, the level of real GDP is projected to decline by about 30 percent (relative to the baseline without demographic change); this amounts to an average reduction of about $1 / 2$ percentage point per year in trend growth. With the composition of the labor force shifting toward a larger share of the elderly, the productivity-adjusted labor supply falls by more than the number of workers. As a result, real GDP per capita also declines in the long run relative to the baseline, albeit to a lesser extent (i.e., by 15 percent relative to the baseline by 2050 or less than $1 / 3$ percent per year on average). Under these estimates, growth of total and per capita GDP will remain positive in absolute terms. Additional age-related expenditures are assumed to be covered through borrowing, until the level of debt reaches 60 percent of GDP, and increases in direct taxes (about 6 percent of GDP in 2050). The current account deficit widens in the long run, as savings fall by more than investment.

The transmission dynamics of a population aging shock are characterized by a twostage process. The stages reflect the relative strength of the two factors driving population aging: rising longevity and declining fertility rates (Figure 1).

- Initially, until 2015 , the effect of rising longevity outweighs that of lower fertility rates, and the adult population and the effective labor supply increase. Output increases by about 3 percent relative to the baseline, as investment and capital-labor ratios increase. Savings rise in line with output, because individuals anticipate longer life spans (i.e., and discount the future less). The ratio of the current account to GDP narrows by about 2 percent by 2015 . Social security expenditures initially rise at a moderate rate; relative to GDP, they are less than 1 percent higher in 2015 than in 2005. This increase is fully financed through borrowing. The rate of growth in public debt is moderate until the late 2020s, with debt rising by about 5 percent relative to GDP.

- $\quad$ As the population aging shock continues to unfold, the effect of lower fertility rates starts to dominate. From around 2015, the effective labor supply starts to decline. Interest rates rise, as savings and investment decline with output. After 2020-25, total and per capita GDP decline. Growth of social security expenditures accelerates, requiring the government to start raising taxes around 2020 to close the financing gap and to maintain the debt ratio on a sustainable path. Public debt approaches 60 percent of GDP by 2050. The current account deficit continues to narrow until about 2030, as investment falls. After 2040, this trend reverses as savings of the aging population decline. 
A delay in fiscal consolidation accelerates the accumulation of public debt and raises the cost of adjustment. If the government delays consolidation by 10 years, to 2030, the fiscal gap would need to be closed through government borrowing. Public debt reaches the targeted level earlier, by 2030 instead of 2050 (Figure 2). The magnitude of the fiscal adjustment needed to close the gap is larger in this case, reflecting higher debt-servicing costs. If consolidation does not take place at all, the debt ratio reaches 60 percent by 2030 , and the fiscal position becomes unsustainable in the long run (Figure 3).

Labor market reforms or boosts to labor-augmenting technological change can help offset the adverse impact of population aging on growth and welfare (Figure 4). An increase in the effective labor supply by about $171 / 2$ percent by 2050 would largely neutralize the welfare implications - as measured by GDP and consumption in the per capita terms-of the increase in the elderly dependency ratio. Labor market reforms and/or a labor-augmenting technological change would also reduce the need for the fiscal adjustment relative to GDP by about 2 percent. Yet, the needed fiscal adjustment would remain significant-about 4 percent of GDP in 2050.

The qualitative conclusions are robust to demographic projections and alternative assumptions on consolidation policies. The results are quantitatively sensitive to alternative demographic projections, with growth and fiscal effects being proportional to the increase in the elderly dependency ratio. However, for a reasonable range of demographic projections, such as the United Nation's high and low variants, for example, the simulated effects of aging on growth and public finances remain broadly similar. ${ }^{13}$ In addition, the results are somewhat sensitive to the assumption on how the fiscal gap is closed. Our simulations assume that the fiscal gap is closed through an increase in direct taxes. This is the most conservative assumption, as the distortionary effects of a direct tax increase on saving and labor supply are likely to be higher than those for indirect taxation and cuts in social security benefits. Under such alternative assumptions, the estimated impact of population aging on growth would be smaller than in the simulations presented in the paper, but, for reasonable values, remain significant.

\section{Conclusion}

Population aging is likely to dampen the outlook for economic growth and living standards (lowering potential growth by $1 / 2$ percentage point per year) and put pressure on public finances in a small open economy like the Czech Republic in the coming decades. It is comforting that the adverse impact on growth can be largely mitigated through what appears to be an achievable increase in labor force participation rates and a labor-augmenting technological change. Yet, even with extensive structural reforms, significant fiscal consolidation will be needed to ensure long-term debt sustainability. The earlier consolidation starts and the deeper are the accompanying structural reforms, the smaller the needed fiscal adjustment will be. To mitigate the macroeconomic effects of population aging, private savings also will need to adjust in preparation for aging. Such an endogenous

\footnotetext{
${ }^{13} \mathrm{UN}(2004)$.
} 
response is assumed in the simulation model, but in practice it will be conditional on good foresight on the part of individuals and proper functioning of the financial markets for longterm savings. 


\section{REFERENCES}

Abel, Andrew B., 1985, "Precautionary Saving and Accidental Bequests," American Economic Review, Vol. 75, pp. 777-91.

Blanchard, O., 1985, "Debt, Deficits, and Finite Horizons," Journal of Political Economy, Vol. 93, pp. 223-47.

Browning, Martin, and Annamaria Lusardi, 1996, "Household Saving: Micro Theories and Micro Facts," Journal of Economic Literature, Vol. XXXIV, (December), pp. 1797855.

Buiter, W.H., 1988, "Death, Birth, Productivity Growth, and Debt Neutrality," The Economic Journal, Vol. 98, pp. 279-93.

Czech Statistical Office, various years, Statistical Yearbook of the Czech Republic, (Prague).

Davies, James, 1981, "Uncertain Lifetimes, Consumption, and Dissaving in Retirement," Journal of Political Economy, Vol. 89, pp. 561-78.

Diamond, P.A., 1965, "National Debt in a Neoclassical Growth Model," American Economic Review, Vol. 55, pp. 1126-50.

European Commission, 2004, “The EU Economy: 2004 Review,” (Brussels).

Faruqee, Hamid, Douglas Laxton, and Steven Symansky, 1997, "Government Debt, LifeCycle Income, and Liquidity Constraints: Beyond Approximate Ricardian Equivalence," IMF Staff Papers, Vol. 44 (September), pp. 374-82.

Faruqee, Hamid and Douglas Laxton, 2000, "Life-Cycles, Dynasties, Saving: Implications for Closed and Small Open Economies," IMF Working Paper 00/126 (Washington: International Monetary Fund).

Faruqee, H., 2002, "Population Aging and Its Macroeconomic Implications: A Framework for Analysis," IMF Working Paper 02/16 (Washington: International Monetary Fund).

_ and M. Mühleisen, 2003, "Population Aging in Japan: Demographic Shock and Fiscal Sustainability," Japan and the World Economy, Vol. 15, pp. 185-210.

Jappelli, T., and M. Pagano, 1989, "Consumption and Capital Market Imperfections: An International Comparison," American Economic Review, Vol. 79, pp. 1088-105. 
International Monetary Fund, 2004, "How Will Demographic Change Affect the Global Economy?" World Economic Outlook, September (Washington: International Monetary Fund).

Laxton, D., and others, 1998, MULTIMOD Mark III: The Core Dynamic and Steady-State Models, Occasional Paper 164 (Washington: International Monetary Fund).

United Nations, 2004, World Population Prospects: The 2004 Revision Population Database. Available via the Internet at www.esa.un.org.

Weil, P., 1989, "Overlapping Families of Infinitely-Lived Agents," Journal of Public Economics,, Vol. 38, pp. 183-98.

Yaari, M.E., 1965, "Uncertain Lifetimes, Life Insurance, and the Theory of the Consumer," Review of Economic Studies, Vol. 32, pp. 137-50. 
Figure 1. Macroeconomic Effects of Population Aging (Deviations from stationary-population baseline levels)
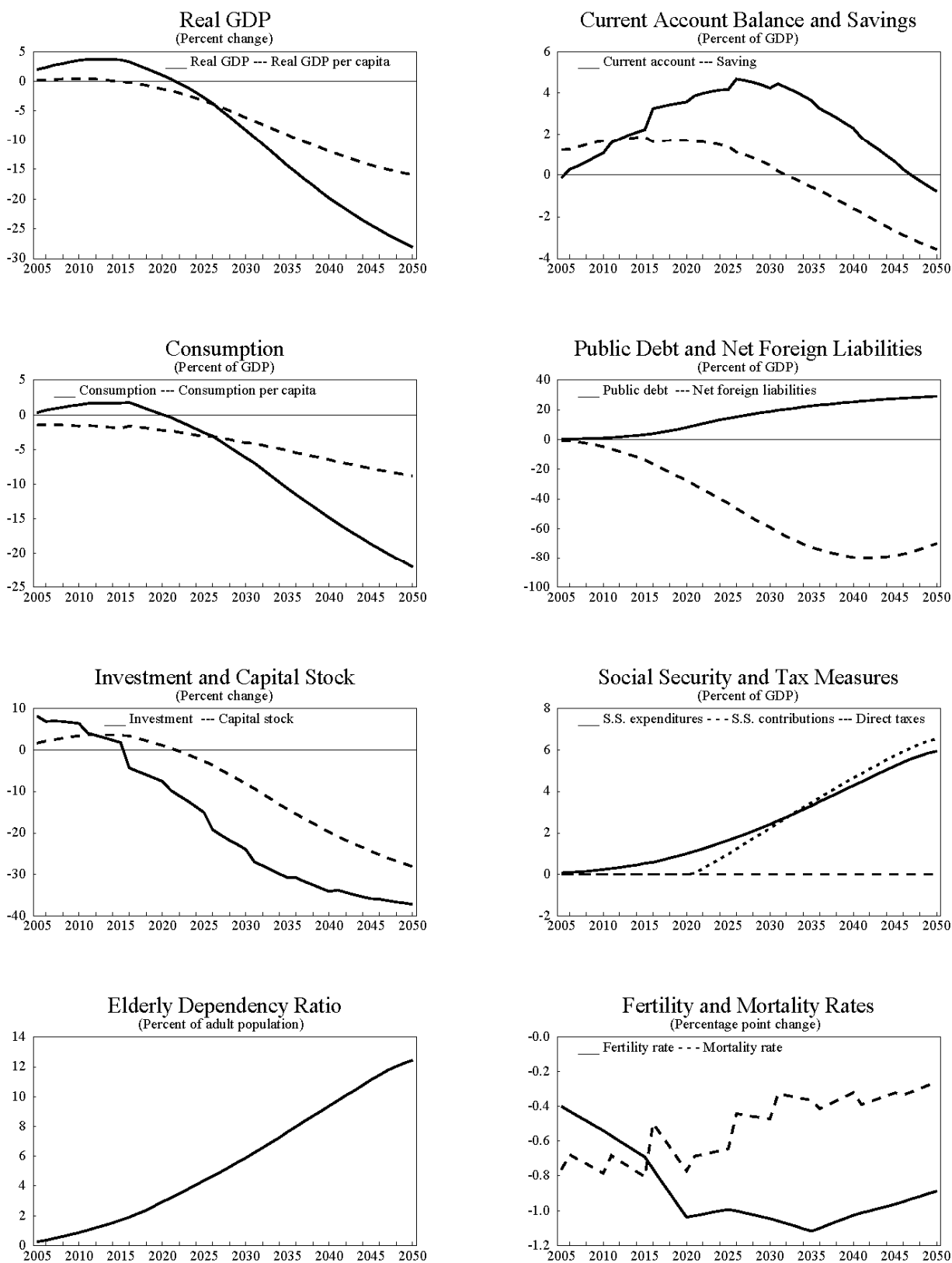
Figure 2. Delayed Fiscal Consolidation (Deviations from stationary-population baseline levels)
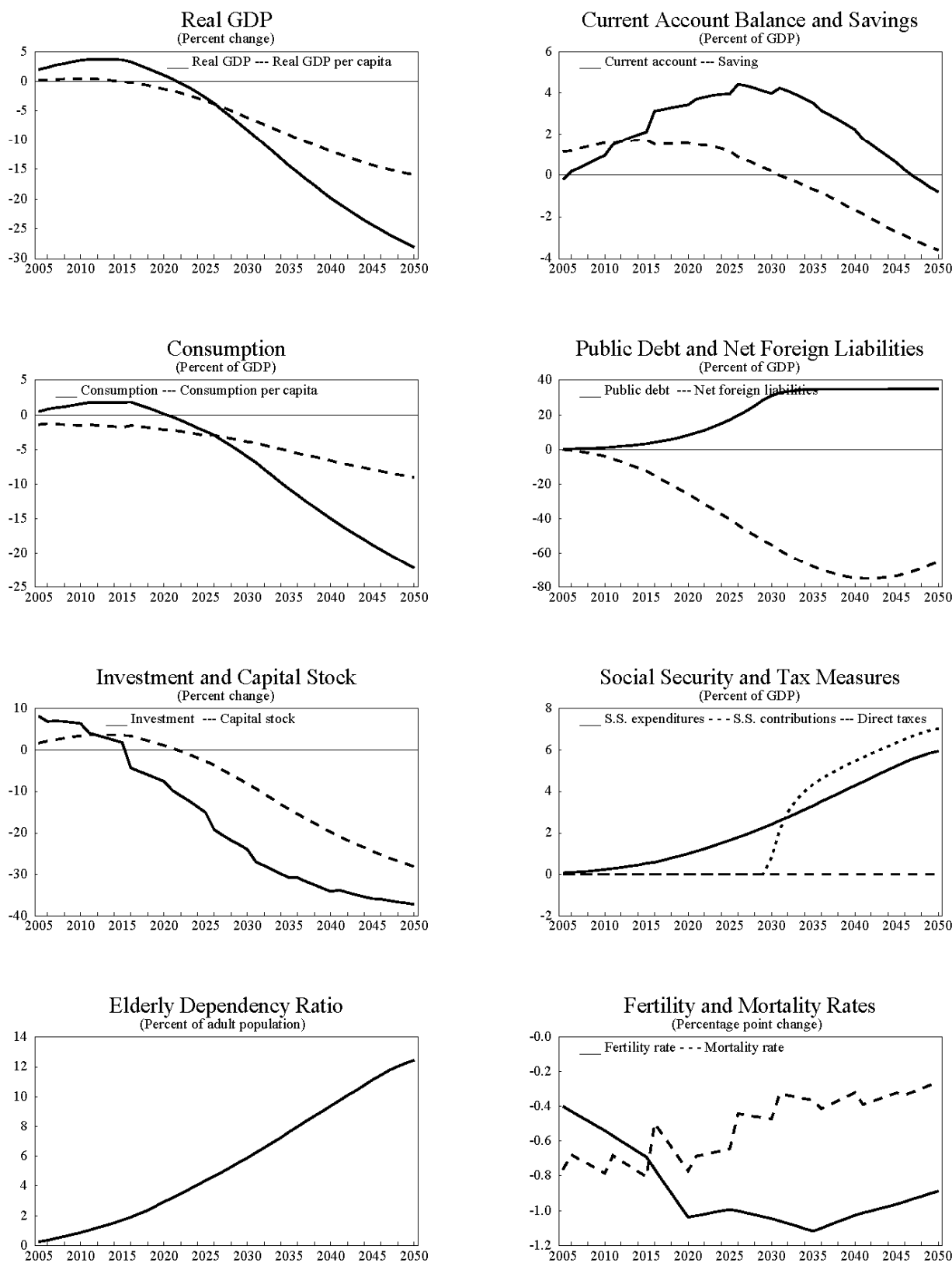
Figure 3. No Consolidation Scenario

(Deviations from stationary-population baseline levels)
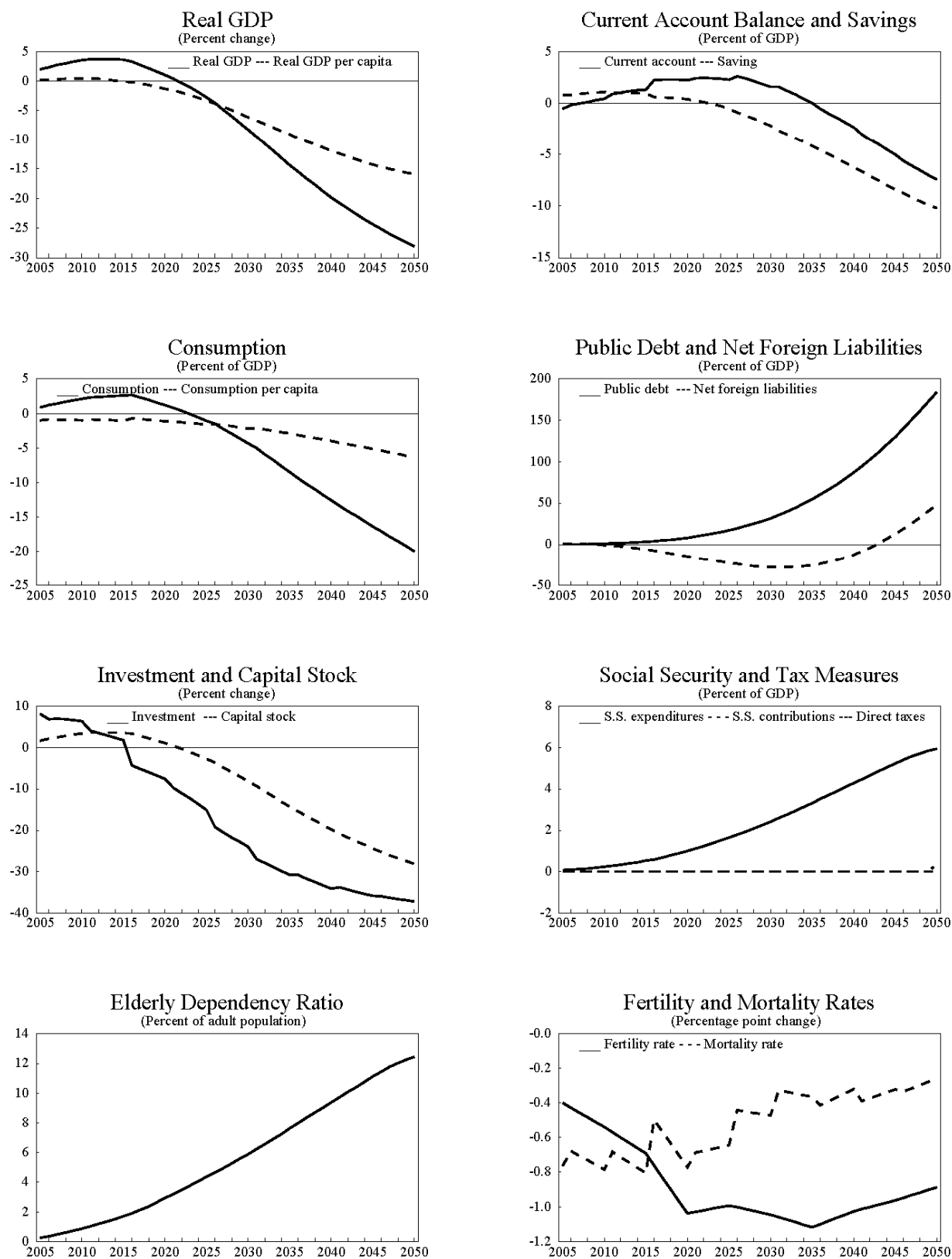
Figure 4. Labor Market Reforms and Labor-Augmenting Technological Change (Deviations from stationary-population baseline levels)
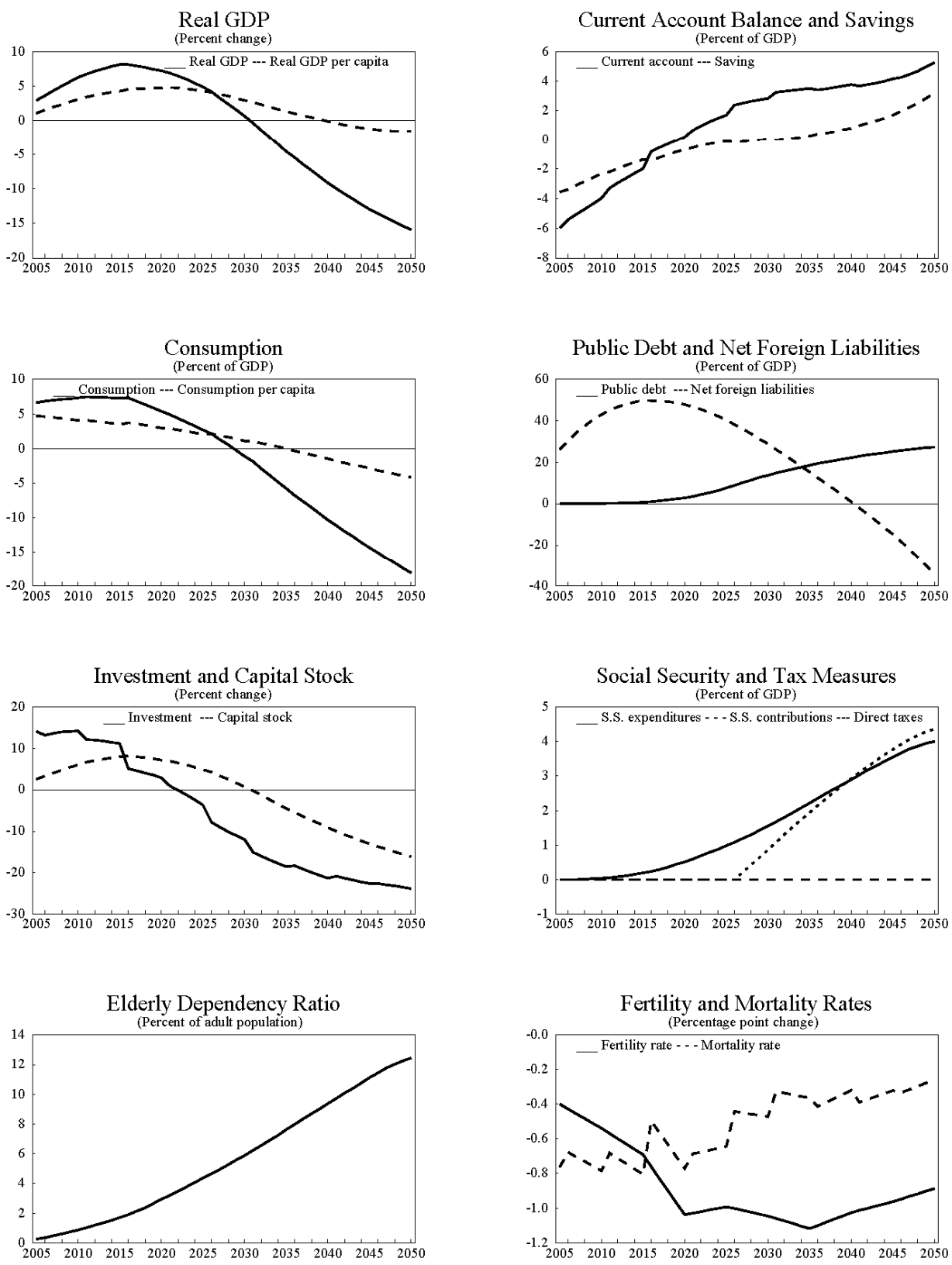


\section{The Description of the Model}

The model is based on Faruqee (2002), which had introduced demographic dynamics into Blanchard's (1985) overlapping generations model. ${ }^{14}$ Demographics are modeled through cohort-specific birth rates and time-varying population growth. Life-cycle dynamics are generated using age-earnings profiles. ${ }^{15}$

\section{Population Growth}

The basic equation for population dynamics is given by:

$$
\frac{\dot{N}(t)}{N(t)}=n(t)=b(t)-p(t),
$$

where $N$ is the population level and $n$ is the growth rate-equal to the difference between the "birth" rate $b$ and the death rate $p,{ }^{16}$ throughout the paper, variables with dots denote derivatives with respect to time. Integrating-up equation (1) over time yields an expression (up to a constant of integration) for the size of the total population at any moment in time:

$$
N(t)=e^{\int_{-\infty}^{t} n(v) d v}=e^{\int_{-\infty}^{t}[b(v)-p(v)] d v} .
$$

Equation (2) shows that population size evolves according to the accumulation of past changes to its growth rate--i.e., the past difference between birth and death rates, which determines the size of the current population as growth factor times the size of the initial population.

\section{Dependency Ratio}

To facilitate analysis of demographic issues, we define measures that characterize the age distribution of the population. Note that the size of the population, which until now has

\footnotetext{
${ }^{14}$ See Buiter (1988) for a description of the model under constant population growth.

${ }^{15}$ Demographic dynamics stemming from changing birth rates are taken as parametric but thus avoids relying on any particular model of fertility.

${ }^{16}$ The birth rate $b$ is defined as the arrival rate of new adults and $N$ is the adult population. With constant birth and death rates, the number of agents belonging to a generation $s$ at time $s$ (i.e., at the time they are born), as a proportion of the contemporaneous population, is given by $n(s, s)=b N(s)$; the number survivors from that cohort at time $t$ is then given by $n(s, t)=b N(s) e^{-p(t-s)}$, where $p$ is the common death rate facing all agents.
} 
been defined in relative terms - vis-à-vis a reference population, can also be defined in aggregative terms - as the sum of existing individuals across all generations (indexed by s): ${ }^{17}$

$$
N(t)=\int_{-\infty}^{t} n(s, t) d s=\int_{-\infty}^{t} b(s) N(s) e^{-p(t-s)} d s
$$

Similarly, we can define the elderly dependency ratio as that proportion of the total population above a certain age as follows:

$$
\phi(t)=\int_{-\infty}^{j(t)} \frac{n(s, t)}{N(t)} d s ; 0<\phi<1,
$$

where $\phi$ measures the relative cohort size, as a share of the total population, of individuals older than some threshold age level--indexed by $j(t)$. Assuming that this age definition does not change, the index $j(t)$ moves with time to include new dependents, who have just reached the threshold age at each moment in time (i.e., $j^{\prime}(t)=1$ ). In the case where birth rates are constant, it can be shown that the dependency ratio $\phi$ would also be constant. ${ }^{18}$ Otherwise, the dependency ratio evolves over time according to the time derivative of equation (4) above:

$$
\dot{\phi}(t)=\frac{n(j(t), t)}{N(t)}-[p+n(t)] \phi(t) .
$$

At each moment in time, the change in the dependency ratio is determined by the relative size of new dependents attaining the threshold age, less the proportion of the elderly $p \phi$ who die each period and accounting for growth in the population base $n \phi-$ i.e., the scaling variable.

\section{Age-Earnings Profiles}

To incorporate the life-cycle dimension in the analysis, we consider age-earnings profiles where labor income initially rises with age and experience, before eventually declining with retirement. We assume that individual labor input (which is inelastically supplied) varies in effective terms across agents from different generations. The effective labor supply (measured in efficiency units) is assumed to have the following time series pattern:

$$
l(s, t)=\left(a_{1} e^{-\alpha_{1}(t-s)}+a_{2} e^{-\alpha_{2}(t-s)}\right) \mu(t) ; t \geq s, a_{1}>0>a_{2}, \alpha_{2}>\alpha_{1}>0 .
$$

\footnotetext{
${ }^{17}$ In this expression, we have assumed a fixed death rate to simplify the discussion. Since the probability of death is independent of age (to allow for aggregation), changes in $p$ have minimal distributional implications, but have important aggregative implications for population growth.

${ }^{18}$ With steady population growth, the dependency ratio would settle down to its long-run value: $\bar{\phi}=e^{-\bar{b} \Delta}$, where $\Delta \equiv t-j(t)$ and $\bar{b}$ are constants.
} 
In this expression, the first exponential term can be interpreted as the decline in an individual's labor supply over time, reflecting (gradual) retirement. This impact on effective labor supply is partially offset, however, by the second exponential term which represents the productivity gains associated with age and experience. ${ }^{19}$ Together, these two factors imply that the behavior of effective labor supply is non-monotonic or hump-shaped-initially rising, but eventually declining over a person's lifetime. The last term $\mu$ in equation (6), which is not age-specific, represents general labor productivity growth that depends on economy-wide considerations (for example, technology). ${ }^{20}$

Assuming equation (6) summarizes the age-specific features underlying differences in labor earnings across cohorts, we can express individual labor income as the product of the aggregate wage rate and individual labor supply:

$$
y(s, t)=w(t) l(s, t)
$$

Thus, for a given wage rate, the relationship between age and earnings will exhibit a similar (hump-shaped) time profile as between age and labor supply; this profile has been documented empirically by age-earnings distributions in a broad cross-section of countries. ${ }^{21}$

Aggregating over all individuals renders total labor income:

$$
\begin{gathered}
Y(t)=\int_{-\infty}^{t} w(t) l(s, t) n(s, t) d s \\
=w(t) L(t)
\end{gathered}
$$

where $L$ is aggregate labor input, also measured in efficiency units. ${ }^{22}$

\footnotetext{
${ }^{19}$ For convenience, we further assume that $a_{1}+a_{2}=1$; so effective labor supply of the cohort born at time $t=0$ is normalized to unity at birth. To insure that effective labor supply is always increasing initially (i.e., at $t=s$ ), we also require: $a_{1}>\alpha_{2} /\left(\alpha_{2}-\alpha_{1}\right)$.

${ }^{20}$ Henceforth, we assume constant productivity growth: $\mu(t)=e^{\mu t}$, where the aggregate productivity index at time zero is normalized to unity.

${ }^{21}$ See for example Jappelli and Pagano (1989). Reorganizing terms implicit in (7), one could also express labor income as a function of a cohort-specific wage $w(s, t)$, commensurate with individual productivity.

22 In Blanchard (1985) and Faruqee, Laxton, and Symansky (1997), age-specific labor incomes were introduced by starting with aggregate labor income and allocating individual incomes according to age-specific weights. The problem with this "top-down" approach is that changes in age distribution have no aggregative implications by construction. Here, we proceed in the opposite fashion or a "bottom-up" approach-i.e., starting with individual labor incomes that differ according to age-specific differences in effective labor and aggregating to obtain total labor income, thus allowing changes in demographic age structure to matter.
} 
Using the definition of individual labor supply in (6), one can also write $L$ as the sum of two components $L_{1}+L_{2}$ - representing aggregates of the factors underlying the ageearnings function in (7). ${ }^{23}$ In the presence of demographic dynamics, the law of motion governing the behavior of aggregate labor input can then be written as:

$$
\begin{aligned}
& \dot{L}(t)=\dot{L}_{1}(t)+\dot{L}_{2}(t) \\
& =b(t) N(t) e^{\mu t}+\left(\mu-p-\alpha_{1}\right) L_{1}(t)+\left(\mu-p-\alpha_{2}\right) L_{2}(t) .
\end{aligned}
$$

Intuitively, equation (9) defines changes in $L$ as depending on the effective labor supply of new entrants to the workforce and the death and productivity changes among existing workers.

\section{Consumption}

Agents are assumed to maximize expected utility over their lifetimes subject to a dynamic budget constraint. Specifically, the evolution of financial assets $a(s, t)$ for an individual or household is determined by its saving, equal to the difference between income and consumption:

$$
\dot{a}(s, t)=(r+p) a(s, t)+y(s, t)-\tau(s, t)-c(s, t)
$$

where $r$ is the interest rate, $y-\tau$ is disposable labor income, and $c$ is consumption, all expressed in real terms (units of consumption). ${ }^{24}$ Ignoring any capital market imperfections, consumption is be based on an agent's permanent income. Explicitly, optimal consumption (with $\log$ utility) is given by: ${ }^{25}$

$$
c(s, t)=(\theta+p)[a(s, t)+h(s, t)] .
$$

\footnotetext{
${ }^{23}$ Specifically, we define: $L_{k}(t)=\int_{-\infty}^{t} l_{k}(s, t) n(s, t) d s$, where $l_{k}(s, t)=a_{k} e^{-\alpha_{k}(t-s)} e^{\mu t}$ for $k=1,2$ and, thus, $\dot{L}_{k}(t)=a_{k} b(t) N(t) e^{\mu t}-\left(\alpha_{k}+p\right) L_{k}(t)$.

${ }^{24}$ The term $p w(s, t)$ in the dynamic budget constraint reflects the efficient operation of the life insurance or annuities market. See Yaari (1965) or Blanchard (1985).

${ }^{25}$ For the simulations, we assume constant relative risk aversion (CRRA) utility; see Blanchard (1985). See Faruqee and Laxton (1999) for a discussion of the implications of CRRA utility and varying the intertemporal elasticity of substitution.
} 
where $\theta$ is the rate of time preference and $h(s, t)$ is a measure of an agent's human wealth-equal to the present value of future labor income. ${ }^{26}$ Because labor income and human wealth eventually decline over a person's lifetime with retirement, the saving behavior implied by equation (11) suggests that agents eventually build up financial wealth $a(s, t)$ to ensure a certain level of retirement consumption. $^{27}$

Consequently, unlike traditional life-cycle models_-for example, Diamond (1965) — the elderly do not dissave or run down financial assets here due to life-time uncertainty. Instead, agents attain a certain target level of financial wealth as a precaution against the possibility of outliving their labor income. The build-up in asset income allows agents to maintain consumption levels well into retirement. This behavioral feature allows the multicohort framework to avoid a common criticism of standard life-cycle models that posit large negative saving rates among retirees.

Aggregating again, total consumption as a function of (financial and human) wealth can be expressed as follows:

$$
C(t)=(\theta+p)[A(t)+H(t)]
$$

where $A$ is aggregate financial wealth and $H$ is aggregate human wealth. Financial wealth consists of domestic equity and bond holdings and, in the open-economy case, holdings of net foreign assets; $A / K+B+F$. As for aggregate human wealth-reflecting the present value of economy-wide labor income streams, its behavior can be characterized as follows:

$$
\begin{aligned}
& \dot{H}(t)=\frac{d}{d t} \int_{-\infty}^{t} h(s, t) N(s, t) d s \\
& =h(t, t) b(t) N(t)+r(t) H(t)-[Y(t)-T(t)],
\end{aligned}
$$

\footnotetext{
${ }^{26}$ For a fixed real interest rate, individual human wealth can be written as: $h(s, t) \equiv \int_{t}^{\infty}[y(s, v)-\tau(s, v)] e^{-(r+p)(v-t)} d v$. Correspondingly, the dynamic equation for an individual's human wealth is given by: $\dot{h}(s, t)=(r+p) h(s, t)-[y(s, t)-\tau(s, t)]$. Given the shape of the age-earnings profile and assuming proportional labor income taxes --i.e., $\tau(s, t)=\tau y(s, t)$, note that human wealth can also be written as: $h(s, t)=h_{1}(s, t)+h_{2}(s, t)$, where $h_{k}(s, t)=\int_{t}^{\infty}(1-\tau) w(v) l_{k}(s, v) e^{-(r+p)(v-t)} d v$ for $k=1,2$.

${ }^{27}$ See Faruqee and Laxton (2000).
} 
where $T$ is total labor taxes and $Y-T$ is total disposable labor income. Equation (13) shows that the incremental change in the stock of aggregate human wealth is influenced by the additional human wealth of the newest generation. ${ }^{28}$

Equations (9) and (13) summarize the role that demographic dynamics play on economic behavior through both supply-side and demand-side channels. On the supply side, changes in the demographic profile of the economy impact the supply of labor, given the differences across age groups summarized in the age-earnings profile. On the demand side, aggregate consumption and saving behavior will also be affected through aggregate human wealth dynamics in the face of life-cycle income and demographic change.

\section{Pension System}

Finally, to complete the model, we describe government policy. A pension system can be introduced into the framework as follows. Consider first the simple case of a lumpsum transfer scheme:

$$
\operatorname{tr}(s, t)=\left\{\begin{array}{l}
-\alpha(t) ; s>j(t) \\
+\beta(t) ; s \leq j(t)
\end{array}\right.
$$

where the transfers $\operatorname{tr}(s, t)$ paid or received by individuals, depending on their age. Younger generations $(s>j(t))$ pay into the system while older agents or pensioners $(s \leq j(t))$ receive a benefit. Redefining the scheme in terms of payroll tax financing is straightforward. In that case, individual contributions would be proportional to wage income: $\alpha(s, t)=\tau_{s s} y(s, t)$.

For any transfer scheme, a full-financing condition can be written as follows:

$$
\int_{-\infty}^{t} \operatorname{tr}(s, t) N(s, t) d s=0 .
$$

This general condition must hold for the transfer scheme to be deemed fully financed (i.e., no unfunded liabilities from the transfer system). Full-financing in the specific case of lumpsum transfer is then given by:

$$
\frac{\beta(t)}{\alpha(t)}=\frac{1-\phi(t)}{\phi(t)} .
$$

Equation (16) shows the well known condition that the benefit-to-contribution ratio must equal the support ratio-i.e., the number of working-age relative to elderly dependents.

\footnotetext{
${ }^{28}$ Given the shape of the labor income profile, the evolution of individual human wealth for the newest generation $h(t, t)$ at each moment in time is:

$\dot{h}(t, t)=\left(r+p+\alpha_{1}\right) h_{1}(t, t)+\left(r+p+\alpha_{2}\right) h_{2}(t, t)-(1-\tau) w(t) e^{\mu t}$
} 
If full-financing is not satisfied, there would exist a financing gap (positive or negative) reflecting the degree of over- or underfunding. In the case of a shortfall, the deficit in social security would have to be closed through general tax revenues or government borrowing.

The dynamics of aggregate human wealth in the presence of social security would be modified as follows:

$$
\dot{H}(t)=h(t, t) b(t) N(t)+r(t) H(t)-[Y(t)-T(t)]-\int_{-\infty}^{t} \operatorname{tr}(s, t) N(s, t) d s,
$$

The dynamic equation now includes the current financing gap from the pension system. If social security benefits are fully financed by contributions, the direct effects of the pension system on total human wealth would net out to zero. ${ }^{29}$ Otherwise, aggregate human wealth would be directly affected by the amount of over- or underfunding of benefits.

\footnotetext{
${ }^{29}$ The evolution of human wealth for the newest cohort is modified as follows under a payroll tax-financed pension scheme:$$
\dot{h}(t, t)=(r+p) h(t, t)+\alpha_{1} h_{1}(t, t)+\alpha_{2} h_{2}(t, t)-\left(1-\tau-\tau_{s S}\right) w(t) e^{\mu t}-\beta(t+\Delta) e^{-(r+p) \Delta} .
$$ 